\title{
Research on Weight Calculation Method for Design Indexes of Marine Shaft System based on the Analysis of Attribute Dependability in Rough Set
}

\author{
Wenjian $\mathrm{LI}^{1, \mathrm{a}}$, Fanming $\mathrm{ZENG}{ }^{2, \mathrm{~b}}$, Jinlin $\mathrm{LIU}^{3, \mathrm{C}}$ \\ ${ }^{1}$ College of Naval Powering Engineering, Naval Univ. of Engineering, Wuhan, 430033, China \\ ${ }^{2}$ College of Naval Powering Engineering, Naval Univ. of Engineering, Wuhan, 430033, China \\ ${ }^{3}$ College of Naval Powering Engineering, Naval Univ. of Engineering, Wuhan, 430033, China \\ aemail: Liwenjian_wh1@163.com, bemail: zengfm201@126.com, 'email: jinlingo@126.com
}

Keywords: Attribute Dependability in Rough Set, Marine Shaft System, Design Indexes, Weight Calculation

\begin{abstract}
Aiming at the problems of every design index weight's distribution and evaluation of marine shaft system, the analysis of attribute dependability in rough set for calculation and analysis was used in this paper— attribute reduction method to remove redundant attributes, retain key information and generate decision-making. The problem of every index's importance of the design of the marine shaft system was solved in this paper, which provided a theoretical method for the weight distribution and the conflict of some factors.
\end{abstract}

\section{Introduction}

As the important connecting equipment between engine and propeller, marine shaft system will not only transfer the engine to the propeller, but also transfer the thrust of the propeller to the marine through the thrust bearing, so as to promote the movement of the marine. And it is the important part of selection and design to the power plant. Therefore, how to obtain the indexes of the marine shaft system accurately, determine the relationship among the indexes and the importance of them is a vital thing.

Rough set theory has obvious advantages in dealing with large amounts of data and eliminating redundant information, so it is widely used in data preprocessing and attribute reduction [1]. Quality function deployment (QFD) method was taken in this article to determine the design indexes of marine shaft system, took the rough set theory to do data preprocessing and attribute reduction [2][3][4][5], extract the key information, and generated decision-making. Based on these methods, taking into account the influence of other factors to the degree of importance of every attribute, at last the results was revised and the results was optimized in this paper.

\section{The weight calculation method for design indexes of marine shaft system}

1: Attribute reduction

Attribute reduction is to find the attributes that can be ignored in the condition attribute set $X$, and finally get a minimum attribute set $X_{0}$ which is core.

$$
\operatorname{POS}_{\text {ind }(X)}(\text { ind }(Y))=\operatorname{POS}_{\text {ind }\left(X_{0}\right)}(\text { ind }(Y))
$$

2: Attribute reduction algorithm

In the information system, if $X=\left(x_{1}, x_{2}, \cdots, x_{n}\right)$ is a family of equivalence relations in domain $U, \quad x_{i}=(i=1,2, \cdots, n)$ is an equivalence relation in the domain $U$; similarly if $Y=\left(y_{1}, y_{2}, \cdots, y_{m}\right)$ is also a family of equivalence relations in domain $U, y_{i}=(i=1,2, \cdots, m)$ is an equivalence relation in the domain $U$. The attribute reduction core of attribute set is:

$$
\operatorname{CORE}(X)=\bigcap_{i \in(1,2, \cdots, n)} X_{i} \quad\left(X_{i}=X-\left\{x_{i}\right\} \wedge \operatorname{dep}_{x_{i}}(Y)=1\right)
$$


That is, the core of the conditional attribute set $X$ is the intersection of all the subsets of the conditional attribute that decision-making attribute set $Y$ strongly depend on. If $\operatorname{dep}_{X}(Y)<1$, we can divide domain $U$ into $U_{1}$ and $U_{2}, U_{1}, U_{2} \subseteq U, U_{1} \cap U_{2}=\varnothing, U_{1} \cup U_{2}=U$, that is to divide information system $T=(U, A)$ into two subsystems, $T_{1}=\left(U_{1}, A\right)$ and $T_{2}=\left(U_{2}, A\right)$. In one subsystem $T_{1}=\left(U_{1}, A\right), \operatorname{dep}_{X}(Y)=1$; and in the other subsystem $T_{2}=\left(U_{2}, A\right), \operatorname{dep}_{X}(Y)=0$. Then we can use this method to simplify $T_{1}=\left(U_{1}, A\right)$

Algorithm:

(1) $\operatorname{CORE}(X)=X ; / *$ we assume $\operatorname{dep}_{X}(Y)=1 * /$

(2) For $i=1$ to $n, X_{0}=X-\left\{x_{i}\right\}$

(3) $\operatorname{dep}_{X}(Y)=\operatorname{card}\left(\frac{\operatorname{POS}_{\text {ind }(X)}(\operatorname{ind}(Y))}{\operatorname{card}(U)}\right)$

(4) If $\left(\operatorname{dep}_{X}(Y)=1\right)$

(5) $\operatorname{CORE}(X)=\operatorname{CORE}(X) \cap X_{0}$

(6) Endfor

(7) Return (CORE $(X))$

3: Weight calculation methods for design indexes of marine shaft system

In the design of shaft system, it is necessary to revise the calculation results for getting the objective conditions that accord with the actual situation because of the complexity of the system. Here we will illustrate by combining the QFD method.

Concrete method:

Set the system $T=(U, A)$, where $U$ is the domain, $A$ is its attribute set, $X$ is the conditional attribute set, and $Y$ is the decision-making attribute set.

(1) calculate the dependability of Y on X;

$\operatorname{dep}_{X}(Y)=\operatorname{card}\left(\frac{\operatorname{POS}_{\text {ind }(X)}(\operatorname{ind}(Y))}{\operatorname{card}(U)}\right)$

(2) calculate the dependability of $\mathrm{Y}$ on the $\mathrm{X}$ after getting rid of $x_{i}$;

$\operatorname{dep}_{X-\left\{x_{i}\right\}}(Y)=\operatorname{card}\left(\frac{\operatorname{POS}_{\text {ind }\left(X-\left\{x_{i}\right\}\right.}(\operatorname{ind}(Y))}{\operatorname{card}(U)}\right)$

(3) obtain the importance of the attribute $x_{i}$;

$\beta_{i}=\operatorname{dep}_{X}(Y)-\operatorname{dep}_{X-\left\{x_{i}\right\}}(Y)$

(4) determine the basic importance vector of the design index of shaft system according to the importance of $x_{i}$,

$g=\left(g_{1}, g_{2}, \cdots, g_{n}\right), g_{i}=\beta_{i} / \sum_{i=1}^{n} \beta_{i}, i=1,2, \cdots, n$

Then determine the important revise factors to the indexes.

(5) The order increment $\Delta O_{i}$ planning to be improved for design index of shaft system

The order increment $\Delta O_{i}$ planning to be improved comes from competitive status $O_{i}$ for design index $x_{i}$ of shaft system (according to the competitive assessment matrix in QFD) and competitive goal $O_{i}^{\prime}$ (according to the resources status and willingness of developers).

$\Delta O_{i}=O_{i}^{\prime}-O_{i}$

(6) The possibility factor $K_{i}$ of the unit improvement

The possibility to realize of unit improvement increment of an attribute $x_{i}$ can be expressed as a constant denoted as $K_{i}$.Account of the possibility to realize, we have the following formula to 
revise $\Delta O_{i}$.

$$
\Delta O_{i}^{\prime}=\Delta O_{i} \times K_{i}
$$

(7) Exclusive advantage $S P_{i}$ for market competition of the attribute $x_{i}$

The exclusive advantage can reflect the importance of the attribute to the design of the shaft system and can also reflect the other competitors' performance, which can be denoted as $S P_{i}$. For example, an attribute which has exclusive advantage reflects the property is important for the design of marine shaft system and other competitors' performance in the field can't make users satisfied. Usually, the exclusive advantage is divided into three grades, corresponding to numerical 1.5, 1.2 and 1 . Through the above concept, a modified factor $\gamma_{i}$ of the importance of attribute $x_{i}$ is

$$
\gamma_{i}=\left(\Delta O_{i}^{\prime} \times S P_{i}\right) / \sum_{i=1}^{n}\left(\Delta O_{i}^{\prime} \times S P_{i}\right), i=1,2, \cdots, n
$$

The revise vector of the importance of every attribute is expressed as $\gamma=\left(\gamma_{1}, \gamma_{2}, \cdots, \gamma_{n}\right)$

Final importance $=$ basic importance $\times$ revise factor. The final importance is expressed as $Z_{i}$. After normalization it is

$$
Z_{i}=\left(g_{i} \times \gamma_{i}\right) / \sum_{i=1}^{n}\left(g_{i} \times \gamma_{i}\right), i=1,2, \cdots, n
$$

\section{Practical application}

Using the QFD method for the design of marine shaft system, we can determine the economy (processing and loss), operation (vibration, noise), reliability (life, maintenance, guarantee) and structural (engine room arrangement, size) four attributes and satisfaction degree SL for design of marine shaft system under these conditions. Through customer surveys we obtained sample set, removed duplicate and redundant data, and got the decision table including the satisfaction levels for attributes and the design of marine shaft system. In the table (table 1), satisfaction levels were divided into low, medium and high grade corresponding to the value of $1,2,3$. The conditional attributes $x_{1}, x_{2}, x_{3}, x_{4}$ refer to four basic attributes of the marine shaft system, the decision-making attribute $j$ on behalf of the satisfaction SL for design of marine shaft system, and $\mathrm{n}$ refers to serial number.

\begin{tabular}{llllllllllll}
\multicolumn{1}{c}{ Table 1} & \multicolumn{7}{c}{ decision-making table } \\
\hline $\mathrm{n}$ & $\mathrm{x}_{1}$ & $\mathrm{x}_{2}$ & $\mathrm{x}_{3}$ & $\mathrm{x}_{4}$ & $\mathrm{j}$ & $\mathrm{n}$ & $\mathrm{x}_{1}$ & $\mathrm{x}_{2}$ & $\mathrm{x}_{3}$ & $\mathrm{x}_{4}$ & $\mathrm{j}$ \\
1 & 1 & 1 & 1 & 1 & 1 & 20 & 2 & 1 & 1 & 2 & 2 \\
2 & 1 & 1 & 1 & 2 & 1 & 21 & 2 & 1 & 1 & 3 & 3 \\
3 & 1 & 1 & 1 & 3 & 2 & 22 & 2 & 1 & 2 & 1 & 3 \\
4 & 1 & 1 & 2 & 1 & 1 & 23 & 2 & 1 & 2 & 2 & 1 \\
5 & 1 & 1 & 2 & 2 & 2 & 24 & 2 & 1 & 2 & 3 & 3 \\
6 & 1 & 1 & 2 & 3 & 3 & 25 & 2 & 1 & 3 & 1 & 3 \\
7 & 1 & 1 & 3 & 1 & 2 & 26 & 2 & 1 & 3 & 2 & 3 \\
8 & 1 & 1 & 3 & 2 & 3 & 27 & 2 & 1 & 3 & 3 & 3 \\
9 & 1 & 1 & 3 & 3 & 3 & 28 & 2 & 2 & 1 & 1 & 3 \\
10 & 1 & 2 & 1 & 1 & 1 & 29 & 2 & 2 & 1 & 2 & 1 \\
11 & 1 & 2 & 1 & 2 & 1 & 30 & 2 & 2 & 1 & 3 & 2 \\
12 & 1 & 2 & 1 & 3 & 3 & 31 & 2 & 2 & 2 & 1 & 1 \\
13 & 1 & 2 & 2 & 1 & 2 & 32 & 2 & 2 & 2 & 2 & 2 \\
14 & 1 & 2 & 2 & 2 & 2 & 33 & 2 & 2 & 2 & 3 & 3 \\
15 & 1 & 2 & 2 & 3 & 3 & 34 & 2 & 2 & 3 & 1 & 3 \\
16 & 1 & 2 & 3 & 1 & 3 & 35 & 2 & 2 & 3 & 2 & 3 \\
17 & 1 & 2 & 3 & 2 & 3 & 36 & 2 & 2 & 3 & 3 & 3 \\
18 & 1 & 2 & 3 & 3 & 3 & 37 & 1 & 2 & 1 & 2 & 2 \\
19 & 2 & 1 & 1 & 1 & 1 & 38 & 2 & 2 & 2 & 2 & 3 \\
\hline
\end{tabular}


According to the decision-making table, we judged whether there were some attributes that can be reduced. The attributes of that didn't need to enter the next step of consideration. In accordance with the attribute reduction algorithm we knew four attributes relative to decision attribute $\mathrm{J}$ couldn't be reduced. Therefore, we organized the four attributes according to importance.

$$
\begin{aligned}
& \operatorname{dep}_{X}(J)=\operatorname{card}\left(\frac{\operatorname{POS}_{\text {ind }(X)}(\operatorname{ind}(J))}{\operatorname{card}(U)}\right) \\
& =\left(\sum V_{J m}-\left(V_{12}+V_{32}+V_{37}+V_{38}\right)\right) / \sum V_{J m}=0.894
\end{aligned}
$$

By the same rule, $\operatorname{dep}_{X-\left\{x_{1}\right\}}(J)=0.421$

$$
\beta_{x_{1}}=\operatorname{dep}_{X}(J)-\operatorname{dep}_{X-\left\{x_{1}\right\}}(J)=0.473
$$

According to the decision-making table, we judged whether there were some attributes that can be reduced. In accordance with the attribute reduction algorithm we knew four attributes relative to decision attribute J couldn't be reduced. Therefore, we organized the four attributes according to importance.

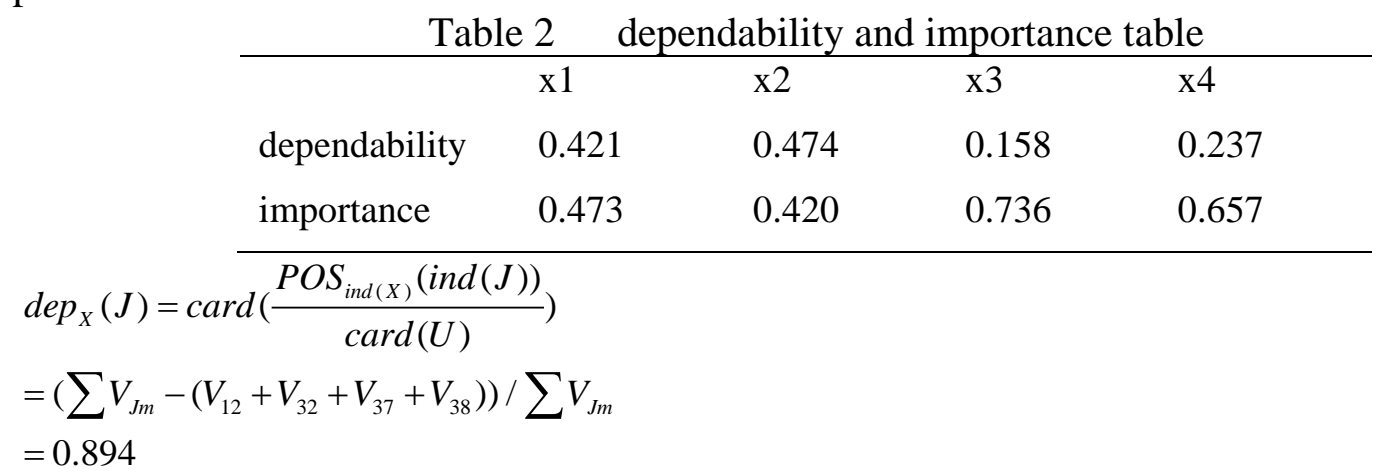

By the same rule, $\operatorname{dep}_{X-\left\{x_{1}\right\}}(J)=0.421, \quad \beta_{x_{1}}=\operatorname{dep}_{X}(J)-\operatorname{dep}_{X-\left\{x_{1}\right\}}(J)=0.473$

Then we got table 2, basic importance vector of four feature attributes could be obtained, $g=(0.207,0.184,0.322,0.287)$

By investigation and expert evaluation, we got the table 3,

Table 3 revise parameters table

\begin{tabular}{ccccc}
\hline & $O_{i}$ & $O_{i}^{\prime}$ & $K_{i}$ & $S P_{i}$ \\
x1 & 4 & 2 & 0.80 & 1.2 \\
x2 & 3 & 1 & 0.85 & 1.5 \\
x3 & 5 & 1 & 0.75 & 1.2 \\
x4 & 4 & 2 & 0.70 & 1.0 \\
\hline
\end{tabular}

By investigation and expert evaluation, we got the relevant revise parameters to four feature attributes as table 3 ,

$$
\gamma_{1}=\left(\Delta O_{1}^{\prime} \times S P_{1}\right) / \sum_{i=1}^{n}\left(\Delta O_{i}^{\prime} \times S P_{i}\right),(i=1,2,3,4)=0.203
$$

By the same rule,

$$
\gamma=\left(\gamma_{1}, \gamma_{2}, \gamma_{3}, \gamma_{4}\right)=(0.203,0.269,0.380,0.148) \quad \text { According to the }
$$

formula, $Z_{1}=\left(g_{1} \times \gamma_{1}\right) / \sum_{i=1}^{n}\left(g_{i} \times \gamma_{i}\right), i=1,2,3,4=0.164$

$Z=(0.164,0.193,0.477,0.166)$

The figure of $Z_{3}$ was maximum, so $x_{3}$ was the most important attribute. 


\section{Conclusion}

The analysis of attribute dependability in rough set was used in this paper to process all aspects of the data for design indexes of marine shaft system, remove the redundant, and retain important data. By calculating we got important degree of every attribute for design indexes of marine shaft system to decision-making.

\section{Acknowledgement}

In this paper, the research was sponsored by the Hubei Provincial Natural Science Foundation (No.2014CFB453)

\section{References}

[1] Yong Zhou, Xingjiang Yang and Yang Xu. Research on Dependability Algorithm of Attribute Reduction [J]. 2004(04):78-80

[2] Zhonghua Han, Chunguang Liu, Changtao Wang, Chonghui Guo, and Tingwu Liao. Applications of Data Mining Approach Based on the Analysis of Attribute Dependability in Rough Set [J]. Joumal of Shenyang Jianzhu University (Natural Science). 2009, 25(5): 1009-1013

[3] Shiqiang Wang, Dengfu Zhang, Duyan Bi, and Lidong Zhang. Two-step Attribute Reduction Method Based on Fuzzy Rough Sets Dependency [J]. Journal of Beijing University of Technology. 2013, 39(6): 828-834

[4] Yongmin Li, Shanjun Zhu, Xianghui Chen, Daiqi Zhang and Zengjin Han. Data mining model based on rough set theory [J]. J T singhua Univ (Sci \& Tech).1999,39(1):110-113

[5] Pawlak Z. Rough Set Approach to Knowledge-based Decision Support [J]. European Journal of Operational Research. 1997,99(1) 